\title{
Pachydema lopadusanorum n. sp. (Coleoptera Melolonthidae) from Lampedusa Island (Sicily Channel, Central Mediter- ranean Sea, Italy)
}

\author{
Ignazio Sparacio',Tommaso La Mantia ${ }^{2 *}$ \& Michele Bellavista ${ }^{3}$
}

1Via Principe di Paternò 3, 90144 Palermo, Italy; e-mail: edizionidanaus@gmail.com

${ }^{2}$ Università degli Studi di Palermo Dip. SAAF, Viale delle Scienze ed. 4, 90128 Palermo, Italy; email: tommaso.lamantia@unipa.it ${ }^{3}$ Via C. De Grossis 7, 90135 Palermo, Italy; e-mail: michele.bellavista@gmail.com

*Corresponding author

ABSTRACT

In this paper the populations of Pachydema Castelnau, 1832 (Coleoptera Melolonthidae) living in Lampedusa Island (Sicily Channel, Central Mediterranean Sea, Italy), so far attributed to $P$. hirticollis (Fabricius, 1787) of North Africa, are examined. The comparison of the main morphological characters between these two populations allowed to attribute those of Lampedusa to a new species that is described in the present work. Faunistic and biological observations on these species are provided

KEY WORDS Scarabaeoidea; Pachydema; taxonomic; new species; North Africa; C-Mediterranean.

Received 11.08.2018; accepted 24.09.2018; printed 30.09.2018; published online 05.10.2018

\section{INTRODUCTION}

The genus Pachydema Laporte de Castelnau, 1832 (Coleoptera Melolonthidae) includes about 100 species distributed throughout the Canary Islands, North Africa, Oman (1 species) and the Middle East (Baraud, 1985; Lacroix, 2005; Král \& Smetana, 2006). Many species of this genus are endemic, uncommon, and with a marked sexual dimorphism.

Among them, P. hirticollis (Fabricius, 1787), reported from Algeria, Tunisia, and Libya, is also present in Italy in Lampedusa and Pantelleria islands, Sicily Channel (Ragusa, 1887, 1893, 1907; Baraud, 1977, 1985; Arnone et al., 1995; Carpaneto \& Piattella, 1995; Sparacio, 1995; Král \& Smetana, 2006; Lacroix, 2007; Ballerio et al., 2010).
The comparison between the Lampedusa and the North African populations of P. hirticollis made it possible to highlight some peculiar morphological differences that allowed to attribute those from Lampedusa to a distinct species herein described.

ACRONYMS AND ABBREVIATIONS. Marcello Arnone collection, Palermo, Italy (CMA); Michele Bellavista collection, Palermo, Italy (CMB); Ignazio Sparacio collection, Palermo, Italy (CIS); Collection of Museum für Naturkunde der Humboldt Universität, Berlin, Germany (ZMHB); Collection of Museo Civico di Storia Naturale "Giacomo Doria", Genova, Italy (MCSNG); Collection of Museum National d'Histoire Naturelle, Paris, France (MNHN); ex/x: specimen/s. Unless otherwise stated, the collector of the beetles in the field is the owner of the collection. 


\section{RESULTS}

\section{Systematics}

Ordo COLEOPTERA Linnaeus, 1758

Familia MELOLONTHIDAE Samouelle, 1819

Subfamilia MELOLONTHINAE Samouelle, 1819

Tribus TANYPROCTINI Erichson, 1847

Genus Pachydema Laporte de Castelnau, 1832

\section{Pachydema lopadusanorum n. sp. (Fig. 1)}

TYPE MATERIAL. Holotypus male: Lampedusa Island (Sicily, Italy), 13.V.1983 (CIS); paratypes, idem, 16 males and 1 female (CIS); idem, legit I. Sparacio, 3 males and 1 female (CMB); Lampedusa Island, Vallone Imbriacola, 19.IV.1987, leg. M. Arnone, 10 males (CIS); idem, 19.IV.1987, leg. M. Arnone, 42 males and 8 females (CA); idem, 18.II.2017, legit T. La Mantia, 2 females (CIS); Lampedusa 1902 - Horn; Lampedusa [V.1886 leg. L. Failla], 4 males and 1 female, collection E. Ragusa (CMC).

Other examined material. Pachydema hirticollis (Fig. 2). Tunisia. Tunis - quedenfeldti, Monastir, Brsk. - Coll. Brenske, 1 ex (ZMHB, syntype Collection Brenske of $P$. quedenfeldti Brenske, 1889). Tunisia, Kamait, 23.IV.1882, G. e L. Doria, Museo Civico di Genova, 7 males and 3 females (MCSNG). Tunisia, 4.VI.1972, G. Fiori, Museo Genova ex coll. G. Fiori (1987), 2 females (MCSNG). Biserta, 23.IV.1994, leg. F. Tagliaferri, 8 males and 1 females (MCSNG). Capo Bon, Korbous, 15.V.1987, 3 males and 1 female (CIS); idem, 26 e 29.IV.1998, 108 males and 18 females (CIS); Sousse, 5.V.1992, 2 females (CIS).

Pachydema demoflysi Normand, 1938. Tunisia, Sbeitla, 16.V.1996, H. Pierotti, 3 males (MCSNG).

DesCription of holotypus. Male. Lenght 12 $\mathrm{mm}$. Head, antennae, palpi, legs, pronotum, and ventral surface black in colour; elytrae red. Pubescence long and yellowish, very dense on the ventral surface.

Head with deep and dense punctures and long and yellowish pubescence. Clypeus wider than long (width clypeus/lenght clypeus $=1.9$ ), fore margin high, slightly emarginated in the middle, with large, very dense and irregular punctures. An- tennae 10-segmented (Fig. 3), club 5-segmented, shorter of the funicle; scape elongated and dilated distally, $2^{\circ}$ segment short and roundish, shorter than the $3^{\circ} ; 3^{\circ}-4^{\circ}$ elongated; $5^{\circ}$ short and transverse. Maxillary palpi with last article fusiform with pointed apex.

Pronotum convex, transverse (width pronotum/ lenght pronotum $=2.1$ ), sub-trapezoidal, maximum width at its posterior third, covered by long and yellowish pubescence, that of the fore margin is directed mainly backwards; pronotal lateral margins subrectilinear in the posterior half after narrow and straight forward; the fore margin is slightly protruding at the middle with fore angles normally shaped; the pronotal bases is widely protruding in the backwards, posterior angles little obtuse; punctures large, deep, and dense.

Scutellum triangular with slightly arched sides, and with a line of large and confluent punctures on the sides. Elytrae a little elongated, slightly rounded on the sides with maximum width at posterior third and yellowish setae on the lateral margins; punctures large and dense, confluent on disc; interstriae obsolete, the $1^{\circ}$ is flat, hardly visible. Humeral callus visible.

Anterior tibiae tridentate, with a little basal tooth, $2^{\circ}$ and $3^{\circ}$ tarsomeres flat and rounded (Fig. 5). Posterior tibiae enlarged at the middle of the inferior margin and, after, strongly dilated towards the apex; posterior tarsi longer than tibiae (lenght tarsi/lenght tibiae $=1.5$ ). First posterior tarsomere shorter than the $3^{\circ}$ tarsomere. Claws bifid.

Pygidium pointed-rounded at apex, finely micro-reticulated with small punctures. Metathoracic wings fully developed.

Aedeagus (Fig. 9) rather long and robust, the parameres apices (in lateral view) are a little elongated and a little pointed.

VARIABILITY. The paratypes males have no substantial morphological differences compared to the holotype. Lenght 11-13.2 $\mathrm{mm}$. The $1^{\circ}$ elytral interstria is always hardly visible, often absent distally. The paratype females are bigger (lenght 14-16.5), with a more convex dorsum, wider distally, reddishbrown in colour, sometimes very dark; antennae and tarsi shorter; punctures of the pronotum large, deep and dense; elytrae smooth with punctures very small and spaced. Propygidium with small punctures on microreticulated surface; pygidium with punctures medium sized and dense. 


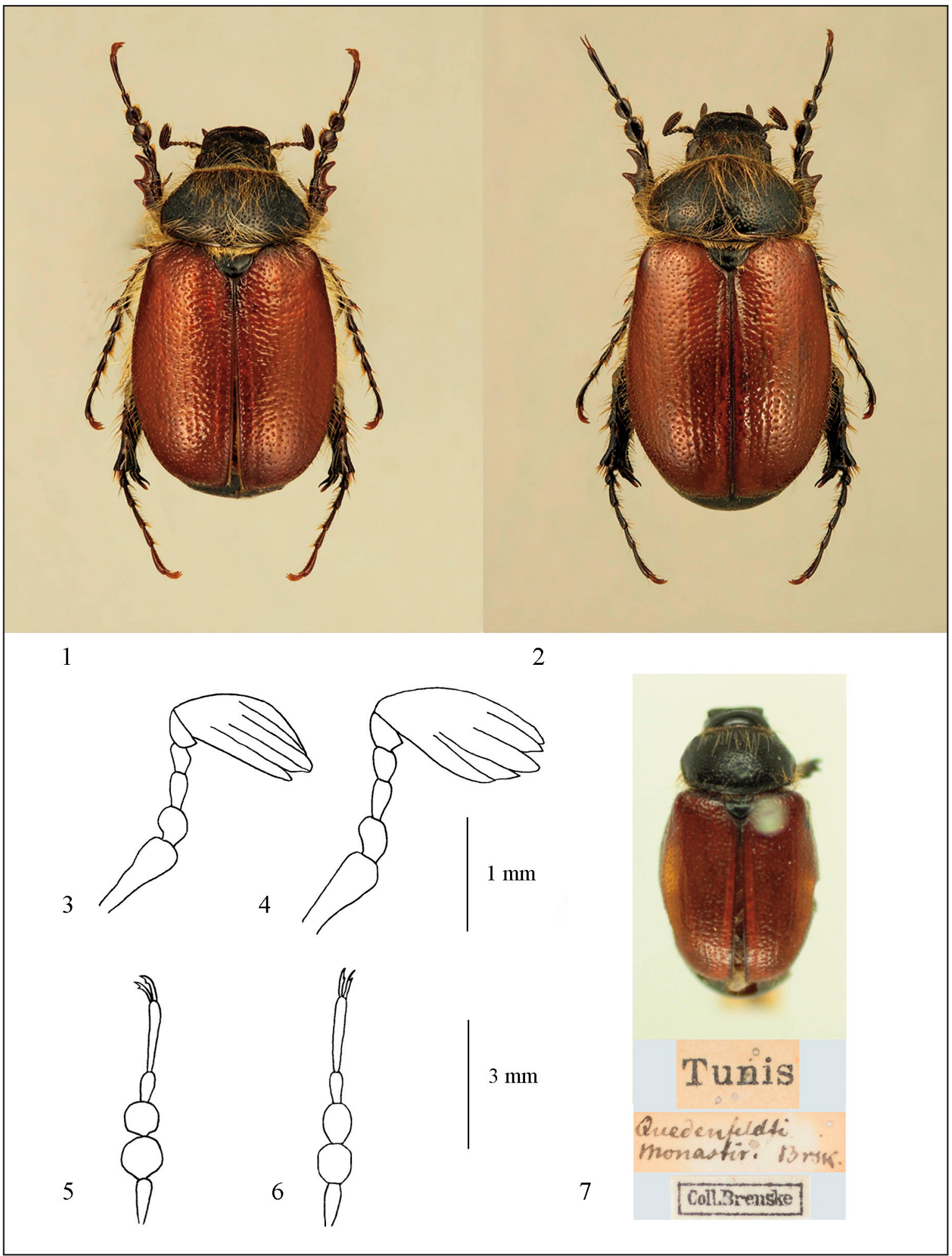

Figure 1. Pachydema lopadusanorum n. sp. from Lampedusa island (lenght $11.8 \mathrm{~mm}$ ). Figure 2. Pachydema hirticollis from Tunisia, Capo Bon, Korbous (lenght $12.4 \mathrm{~mm}$ ). Figure 3. Antennae of $P$. lopadusanorum n. sp. Figure 4. Antennae of $P$. hirticollis. Figure 5. Anterior tarsomeres of $P$. lopadusanorum n. sp. Figure 6. Anterior tarsomeres of $P$. hirticollis. Figure 7. Syntype of $P$. quedenfeldti (from Tunisia, Monastir). 
ETYMOLOGY. Latin name of type locality: "lopadusanorum", that live in Lampedusa. The species is named after the people from Lampedusa island (Sicily Channel, Italy), and in particular to Vincenzo Billeci, Giuseppe Maraventano, Elena Prazzi, Francesco Sanguedolce, and Gerry Sorrentino, who fight for the conservation of nature and human values on that small patch of land surrounded by the sea.

Distribution And Biology. Pachydema lopadusanorum $\mathrm{n}$. sp. is endemic to Lampedusa Island (Sicily Channel, Central Mediterranean Sea, Italy). Adults are active in spring and summer and can be found in flight or on flowers (Sparacio, 1995; Arnone et al., 1995; Ballerio et al., 2010; all sub P. hirticollis).

Status AND Conservation. The few populations and restricted distribution makes $P$. lopadusanorum n. sp. as "Vulnerable", according to the Categories and Criteria of the IUCN Red List of Threatened Species (IUCN, 2017).

Comparative notes. Pachydema lopadusanorum n. sp. appears distinct morphologically from the North African populations of P. hirticollis as follows:

1. Body more elongated, maximum width of the elytrae towards the middle. Second segment of the antennal funicle elongated and roundish, almost as long as the $3^{\circ}$. Pronotum less transverse, more rounded at the sides with medium-size and spaced punctures. First elitral interstria wide, convex, clearly visible throughout the length of the elytrae. Second and third anterior tarsomeres roundish and elongated. Propygidium and pygidium of the females with bigger punctures. Aedeagus (Fig. 8) slender, the parameres apices (in lateral view) are long and pointed. Pachydema hirticollis

2. Body shorter and wider, maximum width of the elytrae at the apical third. $2^{\circ}$ segment of the antennal funicle less elongated and more roundish, shorter than the $3^{\circ}$. Pronotum larger and straighter on the sides, with punctures bigger and denser. $1^{\circ}$ elitral interstria is flat, not very visible, often absent distally. Second and third anterior tarsomeres roundish. Propygidium and pygidium of the females with smaller punctures. Aedeagus (Fig. 9) shorter, the parameres apices (in lateral view) a little elongated and a little pointed.

Pachydema lopadusanorum n. sp.

Pachydema hirticollis is a moderately variable species morphologically. Some different taxa are considered as synonymous of $P$. hirticollis (locus typicus: Africa Dom Vahl) and they are summarized by Baraud (1985), Král \& Smetana (2006), and Lacroix (2007). They, all of North African origin, are: P. barbara Rambur, 1843 (locus typicus: "Côte de Barbarie"), P. nigricans Laporte, 1832 (locus typicus: "femelle, Barbarie, Tunis"), P. quedenfeldti Brenske, 1889 (locus typicus: Monastir), P. rufipennis Burmeister, 1855 (locus typicus: "In Algerien"), P. spreta Fairmaire, 1860 (locus typicus: Tunis).

One syntype of $P$. quedenfeldti (from Tunisia, Monastir; type material is made of four specimens - ZMHB) shows the pronotum with more straight sides, but all the other characters correspond to

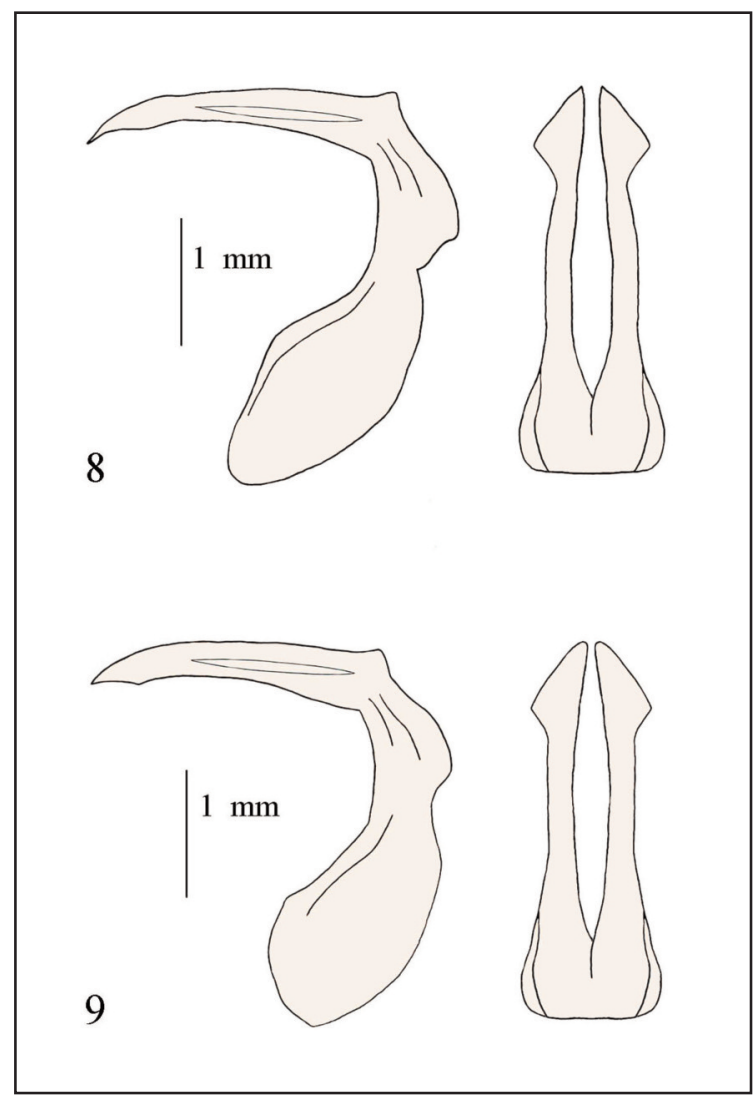

Figure 8. Aedeagus, lateral and dorsal view, of Pachydema hirticollis. Figure 9. Aedeagus, lateral and dorsal view, of Pachydema lopadusanorum n. sp. 
those of other North African populations of P. hirticollis (Fig. 7).

Pachydema demoflysi from Tunisia is distinct from these two species due to the smaller size, the narrower clypeus, smaller punctures of pronotum, and the shape of the aedeagus (see also Baraud, 1985 and Lacroix, 2007).

Pachydema decorosa Normand, 1936 (locus typicus: Le Kef) is similar to P. hirticollis and is little known. It is cited by Král \& Smetana (2006) and Lacroix (2007); for morphological differences see Baraud (1985).

REMARKS. Pachydema hirticollis occurs in Algeria, Tunisia, and Libya. For Italy, Ragusa (1887, 1893, 1907) reported the capture of a pair of $P$. hirticollis in Lampedusa by Luigi Failla Tedaldi in May 1886. The occurrence of this taxon in Lampedusa was confirmed in the following bibliography (Bertolini, 1899; Luigioni, 1929; Porta, 1932; Baraud, 1977, 1986; Du Chatenet, 1986; Carpaneto \& Piattella, 1995; Sparacio, 1995; Král \& Smetana, 2006; Lacroix, 2007). In particular, Gridelli (1960: Cala Madonna and Monte Parrino, IV-V.1954-1956) and Arnone et al. (1995: Cala Galera, Vallone Imbriacola, Spiaggia dei Conigli) provided several localities within Lampedusa. Arnone et al. (1995), moreover, indicated P. hirticollis also for Pantelleria, but this population has not been studied.

All these records from $P$. hirticollis for Lampedusa island must now refer to P. lopadusanorum $\mathrm{n}$. sp.

For these species in Tunisia and Lampedusa, see also: http://www.entomologiitaliani.net/public/ forum/phpBB3/viewtopic.php?t=29334 and http:// www.entomologiitaliani.net/public/forum/phpBB3/ viewtopic.php?t=43785.

\section{ACKNOWLEDGEMENTS}

We are grateful to Marcello Arnone (Palermo, Italy), Alberto Ballerio (Brescia, Italy), Marcello Romano (Capaci, Italy), Roberto Poggi (Museo Civico di Storia Naturale, Genoa, Italy), Giorgio Sabella and Fabio Viglianisi (Dipartimento di Biologia Animale University of Catania, Italy), Joachim Willers (Museum für Naturkunde der Humboldt Universität, Berlin, Germany), and to the staff of Legambiente (Lampedusa, Italy) for their collaboration in the various phases of this study.

\section{REFERENCES}

Arnone M., 2010. Quinto contributo alla revisione della collezione coleotterologica di Enrico Ragusa: Scarabaeoidea. Il Naturalista siciliano, 34: 61-172.

Arnone M., Carpaneto G.M. \& Piattella E., 1995. Arthropoda di Lampedusa, Linosa e Pantelleria. Coleoptera Scarabaeoidea. Il Naturalista siciliano, 19 (Suppl.): 447-468.

Ballerio A., Rey A., Uliana M., Rastelli M., Rastelli S., Romano M. \& Colacurcio L., 2010. Piccole Faune. Coleotteri Scarabeoidei d'Italia. DVD. M. Serra Tarantola ed., Brescia, 1-13 + dvd pp.

Baraud J., 1977. Faune de l'Europe occidentale: Belgique, France, Grand-Bretagne, Italie, Peninsule iberique. IV. Coléoptères Scarabaeoidea. Nouvelle Revue d'Entomologie, Toulouse, 7 (suppl.): 1-352.

Baraud J., 1985. Encyclopédie Entomologique XLVI. Coléoptères Scarabaeoidea. Faune du Nord de 1' Afrique du Maroc au Sinaï. Édition Lechevalier, Paris, 1-651.

Bertolini S., 1899. Catalogo dei Coleotteri d'Italia. Rivista Italiana di Scienze Naturali, Siena, 144 pp.

Carpaneto G.M. \& Piattella E., 1995. Coleoptera Polyphaga V (Lucanoidea, Scarabaeoidea). In: Minelli A., Ruffo S. \& La Posta S. (Eds.), Checklist delle specie della fauna italiana. Calderini, Bologna, 50: $1-18$.

Du Chatenet G., 1986. Guide des Coléopterès d'Europe. Delachaux \& Niestlé, Paris, 480 pp.

Gridelli e., 1960. Coleoptera, 369-407 pp. In: E. Zavattari e coll., Biogeografia delle Isole Pelagie. Rendiconti Accademia Nazionale dei Lincei, 11: 1-471.

IUCN, 2017. The IUCN Red List of Threatened Species. Version 2017-3. http://www.iucnredlist.org (Last access: 05.VIII.2018).

Lacroix M., 2007. Pachydeminae du Monde (Coleoptera, Melolonthidae). Genera et Catalogue commenté. Collections Hannetons, Lacroix, Paris, 450 pp.

Luigioni P., 1929. I Coleotteri d' Italia. Catalogo sinonimico-topografico-bibliografico. Memorie della pontificia Accademia delle Scienze Nuovi Lincei, Roma 13: $1-1160$

Král D. \& Smetana A., 2006. Pachydemini. Pp. 199-207. In: Löbl I. \& Smetana A. (Eds.), Catalogue of Palaearctic Coleoptera. Vol. 3. Scarabaeoidea, Scirtoidea, Dascilloidea, Buprestoidea, Byrrhoidea. Apollo Books, Stenstrup, 690 pp.

Porta A., 1932. Fauna Coleopterorum Italica. 5. Rhynchophora-Lamellicornia. Stabilimento Tipografico Piacentino, Piacenza, 476 pp. 
Ragusa E., 1887. Coleotteri nuovi o poco conosciuti della Sicilia. Il Naturalista siciliano, 7: 25-28.

Ragusa E., 1893. Catalogo ragionato dei coleotteri di Sicilia. Scarabaeidae. Il Naturalista siciliano, 12: 233-239.
Ragusa E., 1907. Coleotteri nuovi o poco conosciuti della Sicilia. Il Naturalista siciliano, 19: 242-252.

Sparacio I., 1995. Coleotteri di Sicilia. I. L'Epos Società Editrice, Palermo, 238 pp. 